Proceedings

\title{
Gelled Emulsions Based on Amaranth Flour with Hemp and Sesame Oils ${ }^{\dagger}$
}

\author{
Carmen María Botella-Martínez *, Juana Fernández-López, José Ángel Pérez-Álvarez and Manuel Viuda-Martos
}

IPOA Research Group, Agro-Food Technology Department, Higher Polytechnic School of Orihuela, Miguel Hernández University, 03312 Orihuela, Alicante, Spain; j.fernandez@umh.es (J.F.-L.); ja.perez@goumh.umh.es (J.Á.P.-Á.); mviuda@umh.es (M.V.-M.)

* Correspondence: c.botella@umh.es

+ Presented at the 1st International Electronic Conference on Food Science and Functional Foods, 10-25 November 2020; Available online: https://foods_2020.sciforum.net/.

Citation: Botella-Martinez, C.; Fernandez-Lopez, J.; Pérez-Álvarez, J.Á.; Viuda-Martos, M. Gelled Emulsions based on Amaranth Flour with Hemp and Sesame Oils. Proceedings 2021, 70, 98. https://doi.org/10.3390/ foods_2020-07713

Published: 10 November 2020

Publisher's Note: MDPI stays neutral with regard to jurisdictional claims in published maps and institutional affiliations.

Copyright: (C) 2020 by the authors. Licensee MDPI, Basel, Switzerland. This article is an open access article distributed under the terms and conditions of the Creative Commons Attribution (CC BY) license (http://creativecommons.org/licenses/by/4.0/).

\begin{abstract}
Gelled emulsion (GE) systems are one of the novel proposals for the reformulation of meat products with healthier profiles. The aim of this research was to obtain a better understanding of the impact of different oils in physicochemical properties, emulsion stability, and thiobarbituric acid reactive substances (TBARs) level for two gelled emulsions based on amaranth flour with hemp oil (GAH) and amaranth flour with sesame oil (GAS). The characterization of these GE was carried out after $24 \mathrm{~h}$ in cooling of $4{ }^{\circ} \mathrm{C}(\mathrm{t} 0)$ and 15 days of freezing at $-23^{\circ} \mathrm{C}(\mathrm{t} 15)$. The spreadability was measured only at $\mathrm{t} 0$ and this revealed that the GAH sample had greater firmness and greater work of shear than the GAS sample. The GAS sample had a higher value of emulsion instability at $\mathrm{t} 0$, with an increase after freezing of $10 \%$ more. For the TBARs, the initial oxidation was higher for GAH, with $1.230 \pm 0.074 \mathrm{mg}$ for the $\mathrm{ma} / \mathrm{Kg}$ sample, which after 15 days of freezing increased to $12 \%$ this amount. Between the emulsions studied, GAS has less consistence and emulsion stability than GAH, so it could be undesirable for some meat products. Thus, GE could be a potential alternative for their application in the development of functional foods.
\end{abstract}

Keywords: hemp; emulsion stability; amaranth flour; spreadability

\section{Introduction}

Nowadays, consumers are more and more interested in healthier foods, including meat products. Therefore, the food industry is shifting to make low-fat or fat-free products [1]. The reason why consumers require healthier meat products is because meat products contain a high amount of saturated fat and salt. An association has been observed between the consumption of saturated fats with diseases such as obesity and hypertension, which leads to cardiovascular problems. So, the reformulation of meat products is necessary [2]. There are several alternatives to formulate healthier meat products, in particular one of them is to use fat substitutes, but it would be desirable to imitate the appearance, sensory, technological, and rheological properties of animal fat [3,4]. However, sometimes the use of fat replacers causes technological problems, especially in texture and flavor of foods. The new fat may affect some desired quality attributes in the reformulated product. Thus, fat replacement is a difficult task [5]. One way to make healthier meat products is by replacing animal fat with vegetable oil sources and this can be done, among other strategies, with the generation of gelled emulsions. Gelled emulsions (GE) can be formulated in different ways with the use of protein together with heat, acidification, or enzyme action. On the other hand, these processes could be carried out with cold gelling agents, which are able to create a network of protein bonds to polysaccharides to generate polymers [6,7]. To form a GE, firstly, a liquid emulsion is formed to generate small drop- 
lets of the dispersed phase suspended in the continuous phase [8]. The GE properties depend mainly on the type or number of hydrocolloids and oil added [5]. Regarding the oils used, both hemp oil and sesame oil offer interesting possibilities. Hemp (Cannabis sativa L.) oil is rich in polyunsaturated (PUFA) fatty acids, especially in linoleic acid and alphalinoleic acid with a ratio $2.1: 1$ to 3:1. Sesame oil make up about $50 \%$ of sesame seeds (Sesamum indicum L.). Sesame oil is used in many processed products, such as a lubricants, cream, insecticides, pharmaceuticals, soap, and salad oil. The main fatty acid composition of sesame oil is about 38 to $47 \%$ linoleic acid and 38 to $44.3 \%$ oleic acid [9]. The aim of this study was to develop oil-in-water $(\mathrm{O} / \mathrm{W})$ gelled emulsions formulated with hemp oil, sesame oil, amaranth flour, and different gelling agents.

\section{Materials and Methods}

\subsection{Materials}

Amaranth flour was obtained from Tentorium Energy S.L. (Tarragona, Spain). Their composition was $11.97 \%$ protein, $6.29 \%$ fat, $2,73 \%$ ash. The hemp oil and sesame oil were available from Laboratorios Almond, S.L., (Librilla, Murcia, Spain). The hemp oil composition was saturated fatty acids $9 \%$, mono-unsaturated fatty acids $11 \%$ and polyunsaturated fatty acids $80 \%$, the main fatty acids were linoleic acid (54\%) and $\alpha$-linoleic acid $(16 \%)$. The sesame oil composition consisted of $14 \%$ saturated fatty acids, $40 \%$ mono-unsaturated fatty acids, and $46 \%$ polyunsaturated fatty acids. The main fatty acids were oleic acid $(46 \%)$ and linoleic acid (44\%). Gellan gum and gel instant were available from Sosa Ingredients S.L., (Barcelona, Spain).

\subsection{Gelled Emulsion Preparation}

Two different types of $\mathrm{O} / \mathrm{W}$ gelled emulsion were formulated, as shown in Table 1. One type of gelled emulsion was prepared by mixing amaranth flour, hemp oil, and gelling agents (gellan gum and gel instant). The other was prepared by mixing amaranth flour sesame oil and gelling agents. The $\mathrm{O} / \mathrm{W}$ gelled emulsions were prepared by mixing instant gel with water for $2 \mathrm{~min}$ at $60^{\circ} \mathrm{C}$ at high speed, using a homogenizer (Thermomix 31, VorwerkEspaña M.S.L., S.C, Spain). Afterwards, the amaranth flour was added and mixed for $1 \mathrm{~min}$ at medium speed. Then, the temperature was turned down to $37^{\circ} \mathrm{C}$ and gellan gum was added and mixed for $2.5 \mathrm{~min}$ at $250 \mathrm{rpm}$. The different oils were added until they were perfectly integrated, then the ingredients were mixed for $5 \mathrm{~min}$ at $37^{\circ} \mathrm{C}$ at $1100 \mathrm{rpm}$. The gelled emulsion was subsequently cooler at $4{ }^{\circ} \mathrm{C}$ during $24 \mathrm{~h}$ after that the parameters were measured and then samples were kept at $-23^{\circ} \mathrm{C}$ during 15 days.

Table 1. Formulation of hemp and sesame oils-in-water emulsion gels.

\begin{tabular}{ccccccc}
\hline Samples $^{1}$ & Water & Flour & Gel Instant & Gellan Gum & Hemp Oil & Sesame Oil \\
\hline GAH & 47 & 10 & 1.5 & 1.5 & 40 & - \\
GAS & 47 & 10 & 1.5 & 1.5 & - & 40 \\
\hline
\end{tabular}

${ }^{1}$ GAH: Gelled emulsion of amaranth flour and hemp oil. GAS: gelled emulsion of amaranth flour and sesame oil. The results are expressed in $\mathrm{g} / 100 \mathrm{~g}$.

\subsection{Instrumental Color Analysis}

The instrumental color parameters of gelled emulsions were measured in the CIEL ${ }^{*}{ }^{*} b^{*}$ color space using a Minolta CM-700 (Minolta Camera Co., Osaka, Japan), with illuminat D65, SCI mode and an observer angle of $10^{\circ}$. Low reflectance glass (Minolta CRA51/1829-752) was placed between the samples and the equipment.

\subsection{Texture Profile Analysis}

The texture of each sample was evaluated using a TA-XT2i texturometer (Stable Micro Systems, Surrey, UK). The spreadability of samples was analyzed with the accessory 
TTC spreadability rig (HDP/ SR, Stable Micro Systems), which was composed of a $90^{\circ}$ male cone probe and five cone-shaped product holders precisely matched female. Both cones were at $25 \mathrm{~mm}$ of distance and the gelled emulsions were forced to flow out at $45^{\circ}$ with a test speed of $3 \mathrm{~mm} / \mathrm{s}$.

\subsection{Gelled Emulsion Stability}

The stability of the emulsion was determined using the procedure from [10]. The determinations were made in triplicate for each GE. The results are expressed in $\mathrm{g} / 100 \mathrm{~g}$ of the sample and were calculated using the following expression:

$\% \mathrm{TEF}=($ Weight of tube with sample-Weight of tube with pellet $) /($ Weight of sample $) \times 100$

\subsection{Lipid Oxidation}

Oxidative stability of GE was evaluated by measuring the change in thiobarbituric acid reactive substances (TBARs). TBAR determination for each sample were performed in triplicate by the method described by [11]. TBARS values were calculated from a malonaldehyde (MDA) standard curve and were expressed as mg MDA/kg sample.

\subsection{Statistical Analysis}

To determine if there were statistical differences between samples, a one-way analyses of variance (ANOVA) was used. It was ascertained whether there were statistically significant differences by means of Tukey's multiple range test with a confidence level of $95 \%$. The data analysis was performed with the statistical package Statistic data editor (SPSS 24).

\section{Results and Discussion}

\subsection{Color Measurement}

The instrument color values of gelled emulsions were affected by the different oil sources and the storage conditions. In Table 2, values for $\mathrm{L}^{*}$ were different for all types. It is also observed that after freezing, the luminosity decreases for both samples, the decrease of this being more pronounced in the GAH sample with an $11 \%$ of reduction.

Table 2. Color parameters at $t_{0}$ and $t_{15}$ of the gelled emulsions.

\begin{tabular}{ccccc}
\hline Samples $^{1}$ & Day & L $^{*}$ & $\mathbf{a}^{*}$ & $\mathbf{b}^{*}$ \\
\hline GAH & 0 & $69.45 \pm 1.91^{\mathrm{a}, \mathrm{b}}$ & $-1.03 \pm 0.21^{\mathrm{d}}$ & $23.52 \pm 0.54 \mathrm{a}^{\mathrm{a}}$ \\
& 15 & $61.83 \pm 2.30^{\mathrm{c}}$ & $-0.52 \pm 0.28^{\mathrm{c}}$ & $23.22 \pm 1.62 \mathrm{a}$ \\
GAS & 0 & $71.47 \pm 0.95^{\mathrm{a}}$ & $0.71 \pm 0.08^{\mathrm{b}}$ & $12.72 \pm 0.22 \mathrm{~b}$ \\
& 15 & $67.37 \pm 0.65^{\mathrm{b}}$ & $0.75 \pm 0.09^{\mathrm{a}}$ & $13.04 \pm 0.44^{\mathrm{b}}$ \\
\hline
\end{tabular}

${ }^{1}$ GAH: gelled emulsion amaranth flour and hemp oil. GAS: gelled emulsion amaranth flour and sesame oil. L*: luminosity; $a^{*}$ : red/green coordinate; $b^{*}$ : yellow/blue coordinate. Values followed by the same lowercase letter within the same column indicate that there are no statistically significant differences $(p>0.05)$ according to the Tukey multiple range test.

Regarding coordinate $\mathrm{a}^{*}$, the sample GAH at time 0 and time 15 presents a more greenish color than the GAS sample. In both samples after freezing the sample became more red. The samples were not affected in the $b^{*}$ coordinate during their storage period. However, they showed statistically significant differences $(p<0.05)$ between both emulsions, the GAH being the one with the highest yellow coloration. These color differences could be due to the color of the oil itself. The color is an essential property for fat analogs as it is one of the characteristics that determines consumers choice of foods [12]. 


\subsection{Textural Properties}

The results of adding hemp or sesame oil in the texture of gelled emulsions, is shown in Table 3. A significant reduction of firmness $(p<0.05)$ and work of shear $(p<0.05)$ is presented in the GAS sample. From the physical point of view, spreadability is the ability of elastoviscoplastic materials to deform [13]. Therefore, these results translate into greater spreadability of the sample GAS with significant differences with the sample GAH.

Table 3. Texture parameters at to to measure the spreadability of samples.

\begin{tabular}{ccc}
\hline Samples $^{1}$ & Firmness (g) & Work of Shear (g.s) \\
\hline GAH & $536.67 \pm 21.28^{\mathrm{a}}$ & $460.00 \pm 8.17 \mathrm{a}$ \\
GAS & $466.67 \pm 11.45^{\mathrm{b}}$ & $366.67 \pm 13.42^{\mathrm{b}}$ \\
\hline
\end{tabular}

${ }^{1}$ GAH: gelled emulsion amaranth flour and hemp oil. GAS: gelled emulsion amaranth flour and sesame oil. Values followed by the same lowercase letter within the same column indicate that there are no statistically significant differences $(p>0.05)$ according to the Tukey multiple range test.

\subsection{Gelled Emulsions Stability}

The results of the stability of the emulsion are calculated by determining the total exudate fluids (TEF), the results obtained for the different samples of gelled emulsions are shown below in Figure 1. The lower the TEF, the greater the stability of the emulsion. It is observed in Figure 1 that there are statistically significant differences $(p<0.05)$ for both samples. At time 0, the sample that presented the greatest stability of the emulsion was GAH (11.32 \pm 0.66$)$, followed by the GAS sample at time $0(29.16 \pm 1.87)$. After freezing, the most stable sample is GAH, but its instability increased by $22.9 \%$ and for GAS the instability is less pronounced with an increase of $10 \%$. Several previous studies have published that the addition of dietary fiber to meat products helps to improve the stability of the emulsion and the rheological properties [13-15]. So, the addition of these emulsions could benefit the stability of the meat product for which they are intended.

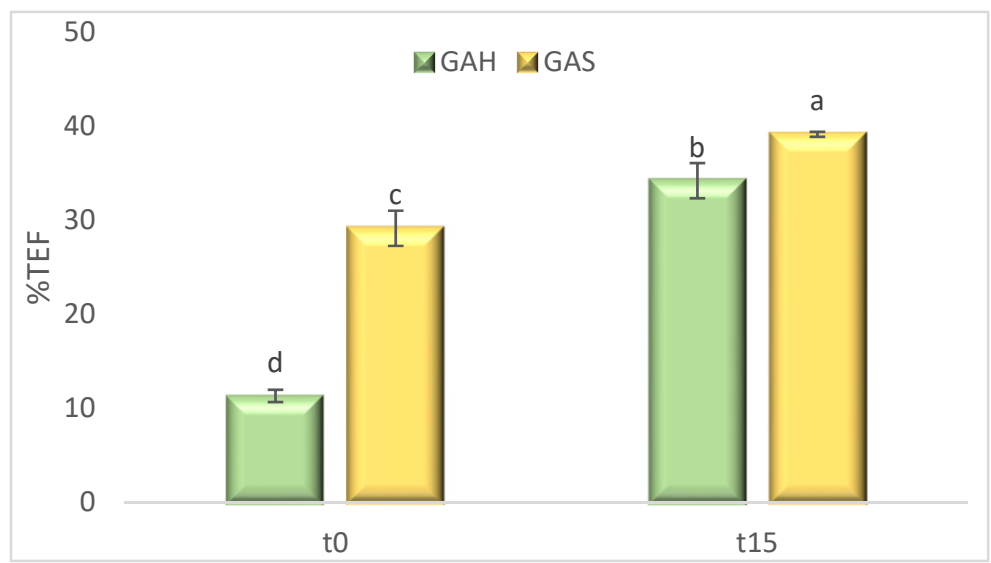

Figure 1. Emulsion stability measured as $\mathrm{g}$ of total liquid expelled/100 g sample. Values followed by the same lowercase letter show that there are no statistically significant differences $(p>0.05)$ according to the Tukey multiple range test.

\subsection{Lipid Oxidation}

Lipid oxidation can have negative effects on the quality of meat products, causing changes in sensory attributes such as smell, taste, color, and texture. Their nutritional quality is also affected [16]. Figure 2 shows the results of the stability to lipid oxidation (TBARs) of gelled emulsions samples. The stability of the samples was evaluated by determining the amount of malonaldehyde, since it is one of the main secondary products of the lipid oxidation process carried out by the decomposition of hydrogen peroxide $[17,18]$. There are significant differences between the samples at 0 time, GAS are the least 
oxidized sample initially with a value of $0.501 \pm 0.167 \mathrm{mg}$ MDA $/ \mathrm{kg}$ of sample. During storage, the GAS sample maintains its oxidation levels, showing no significant differences $(p>0.05)$. However, for the GAH sample, an increase in lipid oxidation of $11 \%$ is observed after conservation, going from values of 1.230 to $1.379 \mathrm{mg} \mathrm{MDA} / \mathrm{Kg}$ of sample. This could be due to the initial lipid oxidation that oils present during their production, as well as their composition, since hemp oil contains $80 \%$ polyunsaturated fatty acids while sesame oil contains only $46 \%$. Even so, the malonaldehyde concentration values obtained for the different samples would not be sensory detected by the consumer, since according to [19] from concentrations of $2 \mathrm{mg} / \mathrm{kg}$ of sample, it is believed that the samples may mean loss of sensory quality and oxidation be perceived by the consumer. This is in accordance with other authors $[20,21]$ who reported that the use of vegetable oils as functional ingredients in food lipid emulsions might be complex due to the high oxidation susceptibility of these unsaturated oils.

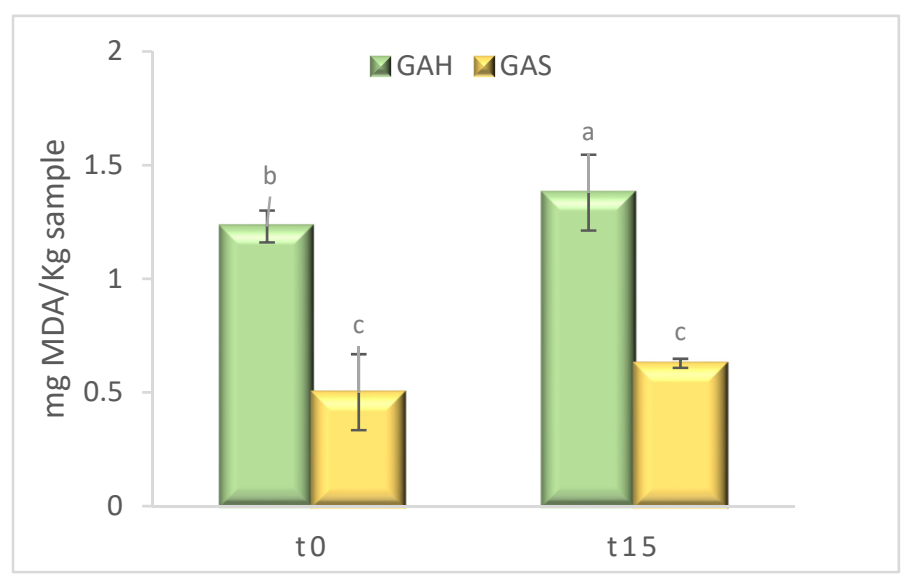

Figure 2. Lipid oxidation by measuring change in TBARs. Values followed by the same lowercase letter show that there are no statistically significant differences $(p>0.05)$ according to the Tukey multiple range test.

\section{Conclusions}

In view of the results obtained, the GAH emulsion showed the highest stability and the best firmness values, although GAS has a higher initial lipid oxidation than GAS and a more greenish color. The color could be a small inconvenience when the gelled emulsion is introduced in meat products to replace the fat. Both emulsions are not viable after freezing because their stability is lost and their lipid oxidation values are triggered. Despite this, gelled emulsions could be a potential alternative for their application in the development of functional foods. So, future studies could investigate the use of oil in water gelled emulsion prepared with healthier combinations of pseudo-cereal flour with seed oils as a possible future fat replacer.

Author Contributions: Conceptualization, M.V.-M. and C.M.B.-M.; methodology, C.M.B.-M., M.V.M., J.F.-L. and J.A.P.-A.; investigation, C.M.B.-M. and M.V.-M.; resources, M.V.-M., J.F.-L. and J.A.P.-A.; writing-original draft preparation, C.M.B.-M.; writing-review and editing, M.V.-M. and J.F.-L.; funding acquisition, J.A.P.-A. All authors have read and agreed to the published version of the manuscript.

Funding: This research received no external funding.

Institutional Review Board Statement: Not applicable.

Informed Consent Statement: Not applicable.

Data Availability Statement: The data presented in this study are available on request from the corresponding author.

Conflicts of Interest: The authors declare no conflict of interest. 


\section{References}

1. Sandrou, K.M.; Arvanitoyannis, I.S. Low-fat/calorie foods: Current state and perspectives. Crit. Rev. Food Sci. Nutr. 2000, 40, 427-447.

2. Jimenez-Colmenero, F.; Salcedo-Sandoval, L.; Bou, R.; Cofrades, S.; Herrero, A.M.; Ruiz-Capillas. C. Novel applications of oilstructuring methods as a strategy to improve the fat content of meat products. Trend Food Sci. Technol. 2015, 44, 177-188.

3. Delgado-Pando, G.; Cofrades, S.; Ruiz-Capillas, C.; Jimenez-Colmenero, F. Healthier lipid combination as functional ingredient influencing sensory and technological properties of low-fat frankfurters. Eur. J. Lipid Sci. Technol. 2010, 112, 859-870.

4. Horita, C.; Morgano, M.; Celeghini, R.; Pollonio, M. Physico-chemical and sensory properties of reduced-fat mortadella prepared with blends of calcium, magnesium and potassium chloride as partial substitutes for sodium chloride. Meat Sci. 2011, 89, 426-433.

5. Paglarini, C.d.S.; Vidal., V.A.S.; Martini, S.; Cunha, R.L.; Pollonio, M.A.R. Protein-based hydrogelled emulsions and their application as fat replacers in meat products: A review. Crit. Rev. Food Sci. Nutr. 2020, in press. doi:10.1080/10408398.2020.1825322.

6. Dickinson, E. Emulsion gels: The structuring of soft solids with protein-stabilized oil droplets. Food Hydrocol. 2012, $28,224-241$.

7. Lam, R.S.H.; Nickerson, M.T. Food proteins: A review on their emulsifying properties using a structure-function approach. Food Chem. 2013, 141, 975-984.

8. Schultz, S.; Wagner, G.; Urban, K.; Ulrich, J. High-pressure homogenization as a process for emulsion formation. Chem. Eng. Technol. 2004, 27, 361-368.

9. Ahmed, I.A.M.; Uslub, N.; Özcan, M.M.; Al Juhaimi, F.; Ghafoor, K.; Babiker, E.; Osman, M.A.; Alqa, H.A.S. Effect of conventional oven roasting treatment on the physicochemical quality attributes of sesame seeds obtained from different locations. Food Chem. 2021, 338, 128109 .

10. Hughes, E.; Cofrades, S.; Troy, D.J. Effect of fat level, oat fiber and carrageenan on frankfurters formulated with 5.12 and $30 \%$ fat. Meat Sci. 1997, 45, 273-281.

11. Rosmini, M.; Perlo, F.; Pérez-Alvarez, J.; Pagán-Moreno, M.; Gago-Gago, M.; López-Santoveña, F.; Aranda-Catalá, V. TBA test by an extractive method applied to pate. Meat Sci. 1996, 42, 103-110.

12. Pintado, T.; Ruiz-Capillas, C.; Jiménez-Colmenero, F.; Carmona, P.; Herrero, A.M. Oil-in-water emulsión gels stabilized with chia (Salvia hispanica L) and cold gelling agents: Technological and infrared spectroscopic characterization. Food Chem. 2015, 185, 470-478.

13. Rezler, R.; Krywdzinska-Bartkowiak, M.; Piatek, M. The influence of the substitution of fat with modified starch on the quality of pork liver patés. LWT-Food Sci. Technol. 2021, 135, 110264.

14. Choi, Y.S.; Lee, M.A.; Jeong, J.Y.; Choi, J.H.; Han, D.J.; Kim, H.Y.; Lee, E.S.; Kim, C.J. Effect of wheat fiber on the quality of meat batter. Food Sci. Anim. Resour. 2007, 27, 22-28.

15. Turhan, S.; Sagir, I.; Ustun, N.S. Utilization of hazelnut pellicle in low-fat beef burgers. Meat Sci. 2005, 71, 312-316.

16. Fernández-Ginés, J.M.; Fernández-López.; Sayas-Barberá, E.; Sendra, E.; Pérez-Álvarez, J.A. Lemon albedo as a new source of dietary fiber: Application to bologna sausages. Meat Sci. 2004, 67, 7-13.

17. De Nuñez Gonzalez, M.T.; Boleman, R.M.; Miller, R.K.; Keeton, J.T.; Rhee, K.S. Antoixidantprperties of dried plum ingredients in ra and precooked pork sausage. J. Food Sci. 2008, 73, 63-71.

18. Bonnes-Taourel, D.; Guérin, M.C.; Torreille, J. Is malonaldehyde a valuable indicator of lipid peroxidation? Biochem. Phar. 1992, 44, 985-988.

19. Trindade, R.A.; Mancini-Filho, J.; Villavicencio, A.I. Effects of natural antioxidants on the lipids profile of electron beam-irradiated beef burgers. Eur. J. Lipid Sci. Technol. 2009, 111, 1161-1168.

20. Jacobsen, C.; Timm, M.; Meyer, A.S. Oxidation in fish oil enriched mayonnaise: Ascorbic acid and low $\mathrm{pH}$ increase oxidative deterioration. J. Agric. Food Chem. 2001, 49, 3947-3956.

21. Taherian, A.; Britten, M.; Sabik, H.; Fustier, P. Ability of whey protein isolate and/or fish gelatin to inhibit physical separation and lipid oxidation in fish oil-in-water beverage emulsion. Food Hydrocol. 2011, 25, 868-878. 